\title{
Syntactic Comprehension in Parkinson's Disease: Investigating Early Automatic and Late Integrational Processes Using Event-Related Brain Potentials
}

\author{
Angela D. Friederici, Sonja A. Kotz, Katja Werheid, Grit Hein, and D. Yves von Cramon \\ Max Planck Institute of Cognitive Neuroscience
}

\begin{abstract}
Parkinson's disease (PD) has been associated with a general impairment of procedures and with an impairment of syntactic procedures in particular. The present study investigated comprehension processes in PD using event-related brain potentials (ERPs). PD patients and controls listened to sentences that were either correct or syntactically or semantically incorrect. The language-related ERP component correlated with semantic processes (N400) was present in both groups. In the syntactic domain, early automatic processes (early negativity) appeared normal in PD, whereas late integrational processes (P600) were modulated by this disease. The present findings suggest that the basal ganglia primarily do not support early automatic syntactic processes during comprehension but rather support processes of syntactic integration.
\end{abstract}

Language is described as consisting of a lexicon containing all lexical elements and a grammar providing the rules according to which syntactic structures are built (Chomsky, 1965; Pinker, 1994). A neural dissociation of lexical-semantic and syntactic processing abilities is suggested by a large number of lesion studies. Patients with left temporoparietal lesions, often diagnosed as Wernicke's aphasia, are more likely to reveal a major lexical-semantic deficit, whereas patients with left inferior frontal lesions, often called Broca's aphasics, are described as revealing a major syntactic deficit (for a review, see Friederici, 1999; Goodglass, 1993). Although these very specific deficits have been reported frequently, it appears that the behavioral patterns of Wernicke's patients and Broca's patients display some variation depending on the particular brain structures involved. For example, Wernicke's patients may also demonstrate syntactic comprehension deficits when the lesion extends beyond the mid portion of the superior temporal gyrus into its anterior portion (Dronkers \& Larsen, 2001).

Recently, Ullman and colleagues (Ullman, 2001; Ullman, Corkin, et al., 1997) claimed a dissociation of language. The lexicon is part of the temporal-parietal/medial-temporal declarative memory system, and grammatical rules are processed by the frontal-basal ganglia procedural system. The

Angela D. Friederici, Sonja A. Kotz, Katja Werheid, Grit Hein, and D. Yves von Cramon, Max Planck Institute of Cognitive Neuroscience, Leipzig, Germany.

This study was partly supported by the Bundesministerium fuer Bildung und Forschung; by Interdisciplinary Center for Clinical Research at the University of Leipzig Grant 01KS9504, Project C09; and by the Leibniz Science Prize, awarded by the German Research Foundation to Angela D. Friederici.

Correspondence concerning this article should be addressed to Angela D. Friederici, Max Planck Institute of Cognitive Neuroscience, PO Box 500 355, Leipzig 04303, Germany. E-mail: angelafr@cns.mpg.de declarative memory system is described as being implicated in the learning, representation, and use of knowledge about facts and events, thereby covering semantic and episodic knowledge. This knowledge is consciously recollected, not informationally encapsulated, and accessible to multiple mental systems. The procedural system covers procedures that are largely implicit. The system itself is informationally encapsulated and has little access to other mental systems (Ullman, 2001). The functional characteristics of the latter system are those of a modular, automatic system, according to the criteria put forward by Fodor (1983). The neuroanatomical description of the two separate systems and their functional specification with respect to language, as proposed by Ullman (2001), is based on the finding that posterior aphasics and patients with Alzheimer's disease demonstrate more errors in generating irregular verb forms (go-went), which are assumed to be stored in the lexicon as a full lexical entry, than in generating regular verb forms $($ cook-cooked), which are taken to be governed by a morphosyntactic rule (add-added). Anterior aphasics and Parkinson's disease (PD) patients, in contrast, show more errors with regular, rule-governed than with irregular verb forms. The latter results are taken to support the notion that grammar is instantiated in the procedural system on the basis of a frontal-basal ganglia circuit, with the basal ganglia playing a prominent role in grammatical processing (Ullman, Corkin, et al., 1997).

Although this view is supported by some studies (for a review, see Ullman, 2001), others are not compatible with this position (see below). In the following, we briefly review the aphasic literature focusing on Broca's and Wernicke's patients, those studies conducted with PD patients that are language-related, and language studies with focal basal ganglia lesions. Moreover, we refer to language-processing studies in healthy adults that bear on the issue of a general dissociation between grammar as the procedural system and the lexicon as the declarative system, as proposed by Ull- 
man and colleagues (Ullman, 2001; Ullman, Corkin, et al., 1997). From this review, it will become apparent that the system called grammar may be multilayered, with the procedural system just constituting one part.

Aphasics with lesions in the left inferior frontal cortex (Broca's aphasics) are characterized by deficits in grammatical processing during language production and during comprehension when the interpretation relies on syntactic information (Berndt \& Caramazza, 1980; Goodglass, 1993; Zurif, Caramazza, \& Myerson, 1972). It is interesting that it is mainly their procedural grammar that is affected, as shown in on-line tasks (Friederici, 1985, 1988; Friederici \& Kilborn, 1989; Haarmann \& Kolk, 1991), whereas their declarative grammatical knowledge, as tested in grammaticality judgment tasks, can be preserved (Linebarger, Schwartz, \& Saffran, 1983). These findings have led to the interpretation that Broca's aphasia is due to a procedural deficit rather than to a loss of grammatical knowledge. The origin of this procedural deficit has been seen in these patients' slow rise time of grammatical information (Friederici, 1988; Friederici \& Kilborn, 1989), in the information's fast decay (Haarmann \& Kolk, 1991), and in a nonexhaustive lexical access (Prather, Shapiro, Zurfi, \& Swinney, 1991).

Wernicke's aphasics, in contrast, clearly demonstrate a lexical-semantic deficit in production and most off-line comprehension tasks but show close to normal performance in on-line semantic priming tasks (Blumstein, Milberg, \& Shrier, 1982; Hagoort, 1993). However, semantic priming varies as a function of automatic or controlled processing. Although automatic priming appears to be intact, controlled semantic priming is impaired in Wernicke's aphasics. It is interesting that a similar off-line versus on-line dissociation is observed in the domain of syntax: Whereas Wernicke's patients show a close to normal performance in on-line comprehension tasks with respect to syntactic aspects (Friederici, 1985), they demonstrate clear syntactic deficits when required to perform off-line comprehension or grammaticality judgment tasks (Bates, Friederici, \& Wulfeck, 1987).

In view of these findings, Blumstein, Milberg, Dworetzky, Rosen, and Gershberg (1991) advanced the view that Broca's aphasia may be due to a deficit in automatic processes-whereas Wernicke's aphasia may be due to a deficit in controlled processes, independent of the semantic versus syntax processing domain. However, note that although this view is orthogonal to the claim put forward by Ullman, Corkin, et al. (1997) with respect to frontal and posterior aphasics, the authors' predictions partly overlap. Both views predict an impairment of automatic syntactic processing in anterior patients and an impairment of controlled lexicalsemantic processing in posterior patients. This notion seems to be supported by the literature discussed above.

Thus, the empirical data are comparable with respect to a subpart of the claim put forward by Ullman, Corkin, et al. (1997) — namely, the frontal cortical part. Their view, however, holds that the frontal-basal ganglia system as a whole represents the procedural system (i.e., the grammar system).
The empirical evidence with respect to the basal ganglia and their possible involvement in language processing is less clear.

PD patients who suffer from a degeneration of dopamine neurons, especially in the substantia nigra of the basal ganglia, have been investigated with respect to their lexicalsemantic, syntactic, and prosodic processing abilities during production and comprehension (M. Lieberman, 2000; P. Lieberman et al., 1992). Studies testing language abilities in simple verbal and semantic tasks have concluded that PD patients show relatively preserved language abilities (Gotham, Brown, \& Marsden, 1988; Mortimer, Pirozzolo, Hansch, \& Webster, 1982; Tyler \& Marslen-Wilson, 1986). Studies investigating PD patients' ability to process emotional prosody consistently report an impairment of this cognitive function (Breitenstein, Daum, \& Ackermann, 1998; Breitenstein, Van Lancker, Daum, \& Waters, 2001; Pell \& Leonard, 2001). M. Lieberman (2000) attributed this impairment to an inability to decode finer temporal suprasegmental structure in the auditory input. Those studies examining syntactic comprehension reported that PD patients consistently experience comprehension difficulties when faced with syntactically complex sentences (Grossman et al., 1991, 1992; Natsopoulos et al., 1993). With respect to these patients' grammatical processing deficit, Grossman et al. (1993) suggested that it depends on a deficient attentional system rather than the grammar as such. A more recent approach views slowed lexical processing in PD as the cause for grammatical comprehension problems in these patients (Grossman et al., 2002). In contrast, Ullman, Corkin, et al. (1997), investigating morphosyntactic aspects in PD patients' language production, reported intact generation of irregular past tense verb forms but deficient generation of regular forms, and they took this finding to indicate an involvement of the basal ganglia in the grammar system. However, note that another study examining spoken language production in PD patients found no specific increase of morphological error but only a smaller proportion of grammatical sentences when PD patients were compared with controls (Murray, 2000), indicating some minor alteration in sentential output. From the combined data, it is not clear what might be the underlying functional deficit causing the observed grammatical processing problems at the sentential level in PD patients.

\section{Patients With Focal Basal Ganglia Lesions}

The direct involvement of the basal ganglia has been investigated in a number of studies with patients suffering from focal subcortical lesions. Although some studies deny a direct role of the basal ganglia in language processing (Nadeau \& Crosson, 1997), other studies assume a direct relationship, in particular in language production (M. P. Alexander, Naeser, \& Palumbo, 1987; Robin \& Schienberg, 1990). A direct test of the possible role of the basal ganglia during language comprehension was undertaken in a recent event-related brain potential (ERP) study that compared patients with left basal ganglia lesions (including the caudate nucleus and putamen as well as a focal lesion of the 
globus pallidus in one patient) and patients with cortical lesions with controls (Friederici, von Cramon, \& Kotz, 1999). The ERP pattern of the basal ganglia patients did not substantially differ from that of controls. Patients with left frontal cortical lesions revealed a deviant brain activation pattern for syntactic processes, in particular for automatic, initial structure-building processes.

Given the data at hand, it is difficult to functionally specify the role of the basal ganglia and/or the frontal-basal ganglia system. Whereas Ullman, Corkin, et al. (1997) held the view that this system's function together with left frontal cortex is the procedural grammar, Grossman and colleagues (Grossman et al., 1991; Grossman, Carvell, Stern, Gollomp, \& Hurtig, 1992) considered the system's major function to relate to attentional factors. Friederici et al. (1999), in contrast, proposed a possible dissociation between the function of the subcortical structures (i.e., basal ganglia on the one hand and the cortical structures on the other, with the latter supporting procedural syntactic aspects in particular). The different claims concerning the possible role of the basal ganglia in grammatical processing, however, are based on studies using different tasks and even different subject groups. Whereas Ullman, Corkin, et al. (1997) used word production tasks and Grossman et al. (1991, 1992) used comprehension tasks with PD patients, Friederici et al. (1999) investigated comprehension in patients with focal lesions of the basal ganglia using the on-line measure of ERPs.

The goal of the present study is to explore the comprehension processes in PD patients as they unfold over time. We used ERPs, a noninvasive, continuous, on-line measure of the brain's electrical activity that is sensitive to specific language-related processes. We chose this measure because it allows us to investigate two temporally and functionally distinct aspects of syntactic processing - namely, early automatic and late integrational processes.

In the following, we briefly review the available evidence on neurologically healthy individuals indicating a dissociation within the domain of syntax into a procedural system, on the one hand, and a controlled processing system, on the other hand.

\section{Early Automatic Versus Late Controlled Syntactic Processes}

In psycholinguistic modeling, the distinction has been made between two stages of syntactic parsing: an early automatic and a late controlled stage. Frazier (1987) proposed an early stage of syntactic processing, during which the input is structured on the basis of word category information, and a second stage, during which integration of the different types of information takes place. Friederici and colleagues (Friederici, 1995; Friederici, Hahne, \& Mecklinger, 1996; Hahne \& Friederici, 1999) found neurophysiological evidence separating grammatical processing into an early stage of initial, first-pass parsing correlated with an early left anterior negativity (ELAN), and a later stage of secondary processes correlated with a late centroparietal positivity, the P600. The early and the late stage were found to be selectively impaired in patients with focal brain lesions. The ELAN component was found to be selectively absent in patients with left frontal cortical lesions (Friederici, Hahne, \& von Cramon, 1998; Friederici et al., 1999) but present in patients with lesions in the basal ganglia (Friederici et al., 1999) as well as in patients with Wernicke's aphasia (Friederici et al., 1998). The P600 component, in contrast, was somewhat reduced in basal ganglia patients and was present in Broca's aphasia but absent in Wernicke's aphasia (Friederici et al., 1998, 1999). Functionally, the finding that the P600 but not the ELAN varies as a function of attentional demands provides further support for the notion of two functionally separable syntactic processes (Hahne \& Friederici, 1999).

Given these data, we reconsidered the grammatical impairment observed in PD patients. So far, no study has approached this issue using ERPs. However, PD is well described with respect to its neural basis and with respect to its nonlanguage cognitive function. PD patients are known to suffer from a degeneration of dopamine-synthesizing neurons in the substantia nigra, which leads to a lack of dopamine in the basal ganglia and its projections to the frontal cortex. This could explain the observed frontal profile of these patients in standard behavioral neuropsychological tests (Caltagirone, Bendetti, \& Gainotti, 1985; Freedman \& Oscar-Berman, 1986). PD patients are found to be deficient in a Stroop test, in particular, when the secondary task is resource demanding, as compared with a less demanding secondary task (Brown \& Marsden, 1991). Some researchers have proposed that PD patients may suffer not from a preattentive deficit in automatic processing but rather from a selectional attention deficit hampering integration processes (Grossman et al., 1993). This differentiation between automatic, preattentive processes and processes of integration makes an interesting prediction with respect to syntactic processes during language comprehension in $\mathrm{PD}$ patients. If the deficit observed in $\mathrm{PD}$ is to be located at the level of integration rather than at the preattentive level, these patients should demonstrate a preserved ELAN component, reflecting early automatic syntactic processes, whereas the P600 component, reflecting late integrational syntactic processes, might be attenuated.

The present study investigates the auditory processing of syntactic and semantic information in patients with PD and in age-matched controls. To differentiate early and late processes, we took electrophysiological measures while subjects listened to sentences that were either correct or semantically or syntactically incorrect. In this investigation, we focused on three language-related ERP components previously established in the literature: the N400, a negativity peaking around $400 \mathrm{~ms}$, correlated with lexical-semantic processes (e.g., Kutas \& Hillyard, 1984); the ELAN, correlated with automatic first-pass parsing processes (e.g., Friederici, Pfeifer, \& Hahne, 1993); and the P600, first observed in correlation with syntactic processes (Hagoort, Brown, \& Groothusen, 1993; Osterhout \& Holcomb, 1992) and later interpreted to reflect processes of syntactic integration (e.g., Kaan, Harris, Gibson, \& Holcomb, 2000). 


\section{Method}

\section{Subjects}

A group of 8 PD patients and a group of 8 age-matched controls participated in the study. The individual patients' histories are displayed in Table 1, including information about age, gender, handedness, and clinical status at the time of testing. Clinical diagnosis and disease severity were assessed by an experienced neurologist. All patients were medicated at the time of testing. None of them showed any signs of dementia or depression.

The control group consisted of 8 subjects ( 3 women) with a mean age of 57 years (ranging from 50 to 71 years of age). There was no statistically significant difference in mean age between patients and age-matched controls $(p>.05)$. All subjects gave informed consent to participate in the study and were paid for their participation.

\section{Material}

The language material was similar to that used in earlier studies (Friederici et al., 1998; Hahne \& Friederici, 2001; Groß et al., 1998). The auditory material was first recorded on analogue tape and then digitized $(20 \mathrm{kHz}, 12$ bit resolution). The recording of the sentences was controlled for pronunciation, prosody, and loudness. To ensure that listeners did not perceive any prosodic or acoustic cues prior to the critical word in the syntactically incorrect sentences, we recorded correct sentences of Types C and D (see examples below). By means of an editing tool, nouns following the preposition were then spliced out from the digitized correct sentence. Only nouns with the same phonological transitions from preposition offset to noun onset and from noun offset to participle onset were used to control for coarticulation. Mean loudness and splicing quality were assessed by an expert. No significant difference in loudness between the spliced and the unspliced conditions was observed.

Subjects listened to 192 sentences spoken by a trained female speaker. Fifty percent of these sentences were correct, $25 \%$ were semantically incorrect, and $25 \%$ were syntactically incorrect. The semantic violation was due to a selectional restriction error (Sentence A: Das Gewitter wurde gebügelt/The thunderstorm was ironed), and the syntactic violation resulted from a word category error (Sentence B: Die Hose wurde am gebügelt/The pants was on ironed; literal translation). A preposition such as am or on must be followed by a noun phrase. Therefore, a verb form following a preposition violates German phrase structure rules. Note that because German is a verb-second language, the passive construction requires the verb in the sentence ending position. For example, a semantically correct form of Sentence A is Das Hemd wurde gebügelt/The shirt was ironed (Sentence C). The correct counterpart of syntactically incorrect Sentence B is Die Bluse wurde am Freitag gebügelt/The blouse was on Friday ironed (Sentence D; literal translation). The critical word (i.e., the sentence final verb) was the same in all conditions.

\section{Procedures}

Subjects were seated in a comfortable chair and listened to the stimuli through loudspeaker boxes. While listening to the sentences, subjects were instructed to fixate on a small star in the middle of a computer screen in front of them and to avoid blinking during the presentation of the star. The star occurred $500 \mathrm{~ms}$ prior to the auditory sentence presentation and remained on the screen until 3,000 ms after the offset of a sentence. The next trial started after an interstimulus interval of $1,000 \mathrm{~ms}$. To avoid possible interferences between language processing and motor demands due to patients' motor impairments, we collected ERPs passively, and no overt response was required.

\section{ERP Recordings}

The electroencephalograph (EEG) was recorded with tin electrodes secured in an elastic cap. Nineteen electrodes were placed according to the International 10-20 system with the following locations: Fz, Cz, Pz, F7, F3, ATL, BL, WL, P7, P3, O1, F8, F4, ATR, BR, WR, P4, P8, and O2 (cf. Sharbrough, 1991). Each EEG channel was amplified with a bandpass from DC to $40 \mathrm{~Hz}$. The EEG was recorded continuously and stored for later analysis at a sampling rate of $250 \mathrm{~Hz}$. The impedance was reduced to below 5 $\mathrm{k} \Omega$. Separate ERPs were averaged (100 ms poststimulus baseline) for each subject at each electrode site. All electrodes were reref-

Table 1

Patient History

\begin{tabular}{|c|c|c|c|c|c|c|c|c|}
\hline $\begin{array}{l}\text { PD } \\
\text { group }\end{array}$ & $\begin{array}{l}\text { Age } \\
\text { (years) }\end{array}$ & Gender & Handedness & MMSE & GDS & $\mathrm{H} \& \mathrm{Y}$ & UPDRS-III & Medication \\
\hline P501 & 70 & M & 1 & 29 & 9 & 1.5 & 29 & L-dopa, cabergoline \\
\hline P502 & 54 & $\mathrm{~W}$ & 1 & 26 & 5 & 1.5 & 18 & Budipine \\
\hline P503 & 47 & W & 2 & 28 & & 3.0 & 45 & $\begin{array}{l}\text { L-dopa, ropinirole, } \\
\text { amantadine }\end{array}$ \\
\hline P504 & 52 & W & 1 & 27 & 6 & 2.0 & 19 & Cabergoline, budipine \\
\hline P505 & 56 & M & 2 & 28 & & 2.5 & 30 & L-dopa, ropinirole \\
\hline P506 & 63 & M & 1 & 30 & 10 & 1.0 & 20 & Pergolide \\
\hline P507 & 67 & M & 1 & 27 & 6 & 3.0 & 33 & L-dopa, ropinirole \\
\hline P508 & 61 & M & 1 & 30 & & 2.0 & 43 & L-dopa, entacapone \\
\hline
\end{tabular}

Note. P503, P505, and P508 completed the Beck Depression Inventory (Beck \& Steer, 1987), with scores of 2, 3, and 4, respectively. For handedness, $1=$ right and $2=$ left. PD $=$ Parkinson's disease; MMSE = Mini-Mental State Examination; GDS = Geriatric Depression Scale (Brink et al., 1982; Yesavage et al., 1983); H \& Y = disease severity as assessed by the Hoehn and Yahr (1967) rating scale, ranging from the initial disease stage (Stage I; unilateral symptoms, no or minimal impairment of daily living) to the final disease stage (Stage V; fully developed motor symptoms, patient is severely disabled and confined to bed); UPDRS-III = motor score of the Unified Parkinson's Disease Rating Scale (Fahn \& Elton, 1987), quantifying tremor, hypokinesia, and rigidity (maximal score: 88 ); $\mathrm{P}=$ participant; $\mathrm{M}=$ man; $\mathrm{W}=$ woman. 
erenced to linked mastoids. Both the vertical and the horizontal electrooculogram were recorded from electrodes placed above and below the right eye and the outer canthus of each eye, respectively. We removed trials with eye blinks or horizontal eye movements and other artifacts from the raw data prior to averaging the data. The ERPs were time locked to the onset of the critical word in each sentence and then calculated from the onset of the critical word until $1,500 \mathrm{~ms}$ poststimulus onset.

\section{Data Analysis}

ERP data for the control group and the patient group for correct and incorrect sentences were analyzed using standard analyses of variance (ANOVAs). Huynh-Feldt corrections (Huynh \& Feldt, 1970) were applied for inappropriate degrees of freedom due to violations of the sphericity assumption. For each violation type (syntactic and semantic), an ANOVA was calculated separately, including the between-subjects factor group (patient vs. control), the within-subject factor condition (correct vs. incorrect), and the within-subject factor region of interest (ROI; anterior vs. posterior). Electrode sites included in the two ROIs were as follows: anterior (F7, F3, ATL, BL, F8, F4, ATR, BR) and posterior (WL, P7, P3, O1, WR, P8, P4, O2). Analyses for midline sites (Fz, Cz, $\mathrm{Pz}$ ) were calculated separately. Critical components observed in the experiment for the patient and the control group were an early anterior negativity, a centroparietal positivity (P600), and a centroparietal negativity (N400). Prior to measuring the mean amplitude of each respective component, we defined time windows by visual inspection of the wave forms in both the patient and the control group and then matched between groups for statistical analyses. The time windows for the respective statistical analyses of the components were as follows: early anterior negativity (100$200 \mathrm{~ms}$ ), P600 (300-700 ms), and N400 (300-500 ms). Significant interactions that included the factor electrode site were normalized with the McCarthy and Wood (1985) procedure. If this procedure was applied, only normalized data are reported.

\section{Results}

ERPs are presented as average wave forms at selected electrode sites for the patient group and the controls. Figure 1 presents the grand average wave form of the ERPs for correct and incorrect targets in the syntactic condition for the patient and control group for the early anterior negativity and for the P600 as well as for targets in the semantic condition for the $\mathrm{N} 400$.

Approximately $8 \%$ of the trials were rejected because of eye blinks, horizontal eye movement, or amplifier blocking in the control group. Eye artifact control measures were applied to the raw data of each patient to increase the number of critical trials in each condition (Pfeifer, Novagk, $\&$ Maess, 1995). The early N1 and P2 components are not visible because the critical word was presented in a continuous speech stream rather than in a word-by-word presentation mode.

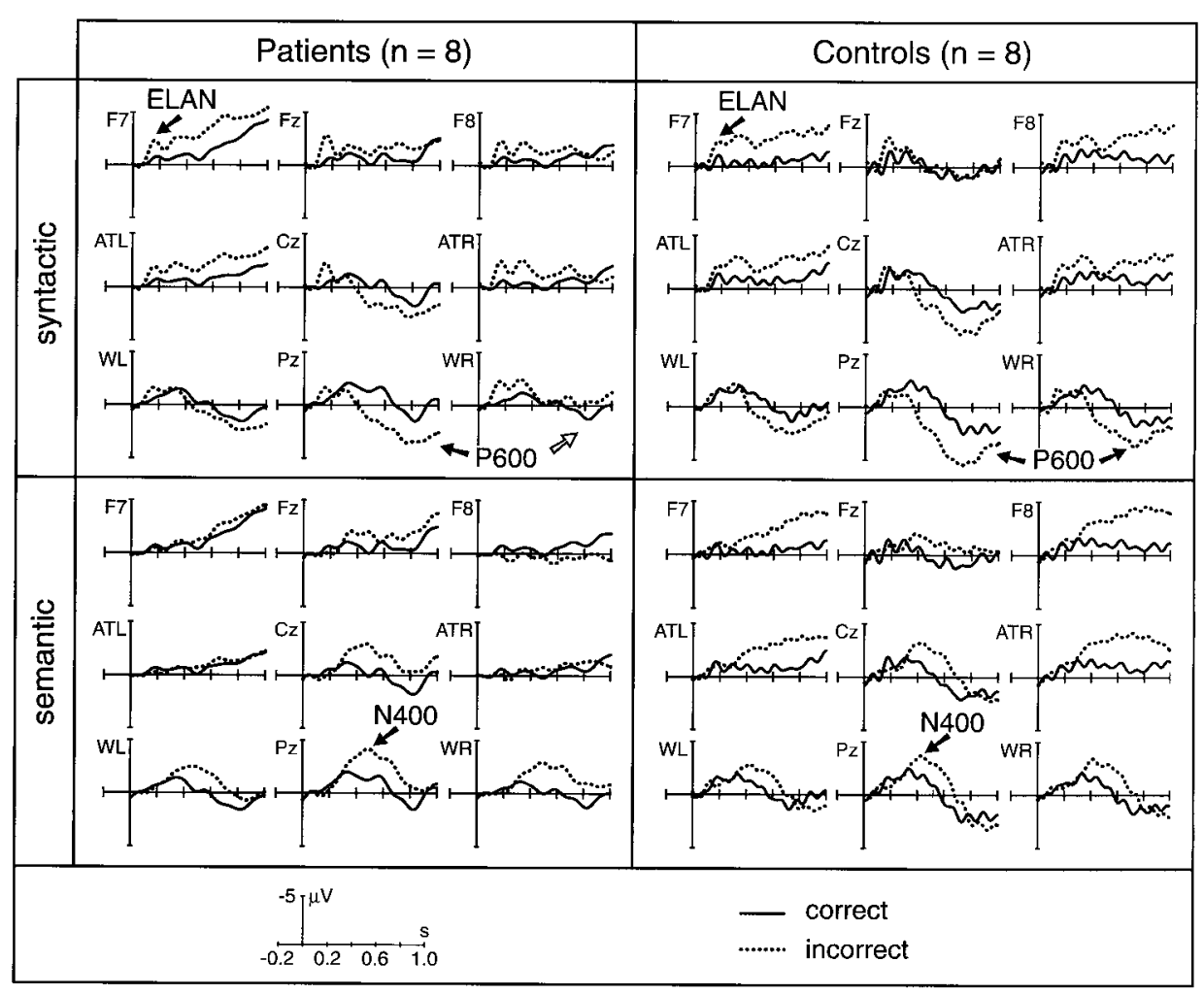

Figure 1. Average event-related brain potentials for the syntactic and semantic conditions at selected electrode sites. The solid line represents the correct sentence condition; the dotted line represents the incorrect sentence conditions. The vertical lines indicate the onset of the critical word. ELAN = early left anterior negativity. 
The omnibus ANOVA of repeated measures for the early anterior negativity resulted in a main effect of condition, $F(1,14)=24.40, p<.001$, and a Condition $\times$ ROI interaction, $F(1,14)=26.87, p<.001$, but no main effect of group $(p>.10)$. Dissolving the interaction revealed a main effect of condition at anterior electrode sites, $F(1$, $14)=40.46, p<.001$, and posterior electrode sites, $F(1$, $14)=6.08, p<.027$. An effect of condition was also found at midline electrode sites, $F(1,14)=15.37, p<.001$. As there is a strong hypothesis in the literature that there should be group differences related to automatic syntactic processes, we looked at the main effects and interaction for each group separately. For the age-matched controls, we found a main effect of condition, $F(1,7)=5.54, p<.050$, and a Condition $\times$ ROI interaction, $F(1,7)=19.91, p<$ .002. In a follow-up analysis of ROI, there was an anterior condition effect, $F(1,7)=13.62, p<.007$, but no posterior condition effect $(p>.10)$ for the controls. A similar pattern emerged for the PD patients. There was a condition effect, $F(1,7)=24.21, p<.001$, and a Condition $\times$ ROI interaction, $F(1,7)=7.90, p<.026$. PD patients did show a large condition effect at anterior electrode sites, $F(1$, $7)=31.08, p<.001$, but they also showed a small condition effect at posterior electrode sites, $F(1,7)=10.51, p<$ .014. At midline electrode sites, controls did not show an early negativity $(p>.10)$, but PD patients did, $F(1$, 7) $=17.30, p<.004$.

The ANOVA for the P600 component displayed no main effect (all $p \mathrm{~s}>.10$ ) but showed a significant Condition $\times$ ROI interaction, $F(1,14)=31.30, p<.001$. Separate analyses by ROI showed a main effect of condition at posterior electrode sites, $F(1,14)=10.06, p<.006$. Furthermore, there was a significant Condition $\times$ Electrode Site $\times$ Group interaction, $F(7,98)=2.41, p<.042$. On the basis of our initial hypothesis on the possible modulations of the P600, we dissolved the three-way interaction. Analyses by group revealed a Condition $\times$ Electrode Site effect in the age-matched controls that approached significance, $F(7,49)=2.34, p<.064$, but not in PD patients $(p>.10)$. To explore subtle group differences, we further analyzed the Condition $\times$ ROI interaction observed in the omnibus ANOVA for both groups. Whereas age-matched controls showed a Condition $\times$ ROI interaction, $F(1,7)=17.62$, $p<.004$, and a dissolved condition effect at posterior electrode sites, $F(1,7)=15.19, p<.005$, PD patients showed a Condition $\times$ ROI interaction, $F(1,7)=14.07$, $p<.007$, that was not significant at posterior electrode sites $(p>.10)$. At midline sites, the main effect of condition only approached significance, $F(1,14)=4.13, p<.061$, and no other main effect or interaction was significant (all $p s>.10)$.

In summary, whereas early syntactic processes reflected in the early anterior negativity occurred for both PD patients (but extended to posterior electrode sites and midline sites) and age-matched controls, PD patients showed a reduced P600 effect for late controlled syntactic processes, as compared with their matched controls. With respect to the N400 component, the ANOVA showed a main effect of condition, $F(1,14)=12.17, p<.003$, but no main effect of ROI or group nor an interaction (all $p \mathrm{~s}>.10$ ). This was also true for the analysis of midline sites, $F(1,14)=12.52, p<.003$. Thus, the processing of correct and incorrect semantic information in PD patients and age-matched controls is comparable.

\section{Discussion}

The goal of this article was to investigate early and late syntactic processes in addition to semantic processes in patients with PD. The central question was whether the degeneration of the dopaminergic neurons in the basal ganglia and its impact on the frontal cortical areas influence early automatic and late integrational processes in the syntactic domain differently. The results demonstrate that early automatic syntactic processes are spared in PD patients' comprehension but that late syntactic integration processes are partially affected. Semantic processes, as expected, are similar to those of controls. In the following, we first discuss the possible influence of medication on ERPs and then discuss the ERP pattern for the semantic processes and the syntactic processes in more detail.

\section{The Possible Influence of Medication}

The argument could be raised that the medical treatment of the patients in this study could have affected the ERP pattern. However, if this were the case, the late syntactic component should not have been affected selectively; the early syntactic component and the N400 would also have been affected. As one can see from the data, this is clearly not the case, as we observed only a modulation in the amplitude of the P600. Furthermore, there is no report of either a selective or a general effect on the ERPs' amplitude as a function of the medical treatment used here.

Studies investigating the effect of L-dopa therapy on ERPs in PD patients report only modulations in the ERPs' latency. A prolonged P300 latency before treatment was shown to be reduced after treatment, however, with no effect on the amplitude (Oishi, Mochizuki, Hara, Du, \& Takasu, 1996; Sohn, Kim, Huh, \& Kim, 1998). The application of bromocriptine in healthy adults caused a prolonged P300 latency but, again, no effect on its amplitude (Nishimura, Ogura, \& Ohta, 1995). Thus, these findings suggest that the amplitude of a late positivity (i.e., the P300 component) is not affected by the type of medication at issue. This allows us to discuss the observed ERP effects independently of the medical treatment.

\section{Semantic Processes}

Control subjects revealed an N400 component in correlation with the processing of semantically incorrect sentences. The amplitude of the N400 effect for these agematched controls was somewhat smaller than that usually observed in young adults. However, the time course and the distribution were comparable to the N400 effects found for auditory sentence processing in previous studies (Friederici et al., 1993, 1998; Holcomb \& Neville, 1991). 
PD patients demonstrated an N400 that was similar to that of their age-matched controls, suggesting that semantic processing, as tested in the passive sentences of the present study, is intact. This finding is in line with earlier behavioral studies reporting normal performance for PD patients on semantic tasks (Levin, Llabre, \& Weiner, 1989; Tyler \& Marslen-Wilson, 1986) and on tasks relying on lexical knowledge (Ullman, Corkin, et al., 1997).

\section{Syntactic Processes}

Early and late syntactic processes measured by the listener's brain reaction to phrase structure violation are differentially affected by PD. The early anterior negativity is present in PD patients, reflecting early automatic processes, whereas the P600, reflecting late processes of syntactic integration, is reduced and not significant in PD patients. The early anterior negativity has a somewhat different distribution in PD patients, as compared with controls. Whereas it is restricted to frontal lateral electrodes in controls, it extends to temporal and midline electrodes in PD patients. So far, we can only speculate on the possible cause of the more extended distribution of the early negativity in PD. It may be a reflection of the degeneration of dopaminergic neurons of the substantia nigra that leads, in a cascade of processes in various subcortical structures, to a disinhibition (G. E. Alexander \& Crutcher, 1990; Baldini, Nappi, Tassorelli, \& Martignoni, 2000; Graybiel, 1990). The resulting hyperactivity may be responsible for the more diffuse distribution of this particular ERP component, which has been explained by two generators-namely, one in the left inferior frontal and one in the left temporal cortex (Friederici, Wang, Herrmann, Maess, \& Oertel, 2000). Another possibility is that the relative strength of the frontal and the temporal generators is slightly different in PD patients and in controls (Friederici et al., 2000). Independent of this distributional issue, the present early anterior negativity observed in PD demonstrates that the processes of early structure building do not rely directly on the intact function of the basal ganglia.

The dissociation between the early and the late syntactic processes provides some interesting insights into the function of the basal ganglia during syntactic processes. The present data suggest that functional deficits of the basal ganglia affect late integrational rather than early automatic syntactic processes during comprehension. The alteration of the late syntactic integration processes may be responsible for the comprehension deficits observed in PD patients (Grossman et al., 1993). The present finding appears to be in disagreement with the claim that PD (and, thereby, a basal ganglia dysfunction) has a major impact on the procedural grammatical knowledge (Ullman, Corkin, et al., 1997). Ullman et al. based their argument (a) on the definition of the frontal-basal ganglia circuit as the procedural system and (b) on the findings that patients with PD perform weakly on generating regular verb forms as compared with irregular verb forms. The present and earlier (Friederici et al., 1999) ERP findings as well as the functional magnetic resonance imaging (fMRI) results from Ullman, Bergida, and
O'Craven (1997) challenge the view that the basal ganglia play a crucial role in the use of syntactic procedures. Ullman, Bergida, and O'Craven (1997) found basal ganglia activation for both regular and irregular verbs, with even stronger activation for irregular verbs.

Positron emission tomography and fMRI studies investigating syntactic processes during sentence comprehension are not univocal with respect to a possible involvement of the basal ganglia: Whereas some report an involvement of the structure (Moro et al., 2001), others do not (Friederici et al., 2000; Indefrey, Hagoort, Herzog, Seitz, \& Brown, 2001; Inui et al., 1998; Just, Carpenter, Keller, Eddy, \& Thulborn, 1996; Stromswold, Caplan, Alpert, \& Rauch, 1996).

A unified interpretation of PD's language behavior in the present on-line electrophysiological comprehension study and in a number of off-line syntactic tasks in comprehension (Grossman et al., 1993; Natsopoulos et al., 1993) and during production (Ullman, Corkin, et al., 1997) may lie in the distinction between early automatic structure-building syntactic processes and more conscious syntactic processes, such as the generation of different verb forms (Ullman, Corkin, et al., 1997), sentence-judgment and question-answering tasks (Grossman et al., 1991, 1993), and the comprehension of sentences demanding syntactic working memory resources (Natsopoulos et al., 1993). Let us consider this interpretation in the light of studies investigating language and other cognitive functions in PD patients.

Researchers seem to agree on the notion that PD patients provide a behavioral pattern in neuropsychological tests seen in frontal patients (Caltagirone et al., 1985; Grossman et al., 1993; Phillips \& Carr, 1987; Tyler \& MarslenWilson, 1986) showing a decrement in performing the Wisconsin Card Sorting Test (Heaton, 1981) and related tests requiring executive control. They disagree, however, on the description of the underlying deficit and thereby on the functional description of the basal ganglia.

Some researchers claim that the underlying deficit in PD patients is best described as a deficit in procedural knowledge, be it in a general sense (Phillips \& Carr, 1987) or in a more specific way (Ullman, Corkin, et al., 1997). This view does not easily hold up given the finding that PD patients are shown to achieve procedural knowledge (although they required a large number of repetitions; PascualLeone et al., 1993) and given the present ERP data demonstrating that PD patients are comparable with their matched controls with regard to automatic structure-building syntactic processes during comprehension.

Other researchers have proposed that the deficit underlying PD patients' behavior may be located not at the preattentive level but rather at a level in which effort-demanding selective attention that allows the anticipation and integration of processing requirement is in order (Grossman et al., 1993) This notion is supported by a recent ERP experiment using a standard odd-ball task that showed that the component reflecting automatic processes (NA) was less impaired than the one reflecting attention-controlled processes (Tachibana, Aragane, Miyata, \& Sugita, 1997). To the extent that this general distinction can be mapped onto the distinction between early automatic and late integrational 
syntactic processes, the present results are in agreement with this proposal. PD patients' automatic syntactic processes are preserved, whereas late processes of syntactic integration are modulated.

\section{Conclusion}

The present ERP findings from PD patients together with earlier ERP studies on patients with subcortical and cortical left frontal legions (Friederici et al., 1999) suggest a different functional role for the basal ganglia and the frontal cortex within the basal ganglia-cortical circuit-at least during sentence comprehension. The main function of the left frontal cortex appears to support automatic structurebuilding processes, whereas the basal ganglia do not seem to be critically involved in these early syntactic processes.

\section{References}

Alexander, G. E., \& Crutcher, M. E. (1990). Functional architecture of basal ganglia circuits: Neural substrates of parallel processing. Trends in Neurosciences, 13, 266-271.

Alexander, M. P., Naeser, M. A., \& Palumbo, C. L. (1987). Correlations of subcortical CT lesion sites and aphasia profiles. Brain, 110, 961-991.

Baldini, F., Nappi, G., Tassorelli, C., \& Martignoni, E. (2000). Functional changes of the basal ganglia circuitry in Parkinson's disease. Progress in Neurobiology, 62, 63-88.

Bates, E., Friederici, A. D., \& Wulfeck, B. (1987). Grammatical morphology in aphasia: Evidence from three languages. Cortex, 23, 545-574.

Beck, A. T., \& Steer, R. A. (1987). Beck Depression Inventory manual. New York: Psychological Corporation.

Berndt, R. S., \& Caramazza, A. A. (1980). Redefinition of the syndrome of Broca's aphasia: Implications for a neuropsychological model of language. Applied Psycholinguistics, 1, 225278.

Blumstein, S. E., Milberg, W., Dworetzky, B., Rosen, A., \& Gershberg, F. (1991). Syntactic priming effects in aphasia: An investigation of local syntactic dependencies. Brain and Language, 40, 393-421.

Blumstein, S. E., Milberg, W., \& Shrier, R. (1982). Semantic processing in aphasia: Evidence from an auditory lexical decision task. Brain and Language, 17, 301-315.

Breitenstein, C., Daum, I., \& Ackermann, H. (1998). Emotional processing following cortical and subcortical brain damage: Contribution of the fronto-striatal circuitry. Behavioural Neurology, 11, 29-42.

Breitenstein, C., Van Lancker, D., Daum, I., \& Waters, C. (2001). Impaired perception of vocal emotions in Parkinson's disease: Influence of speech time processing and executive functioning. Brain and Cognition, 45, 277-314.

Brink, T. L., Yesavage, J. A., Lum, O., Heersema, P. H., Adey, M., \& Rose, T. S. (1982). Screening tests for geriatric depression. Clinical Gerontology, 1, 37-43.

Brown, R. D., \& Marsden, C. D. (1991). Dual task performance and processing resources in normal subjects and patients with Parkinson's disease. Brain, 114, 215-231.

Caltagirone, C., Bendetti, N., \& Gainotti, G. (1985). Dementia in Parkinson's disease: Possible specific involvement of the frontal lobes. International Journal of Neuroscience, 26, 15-26.

Chomsky, N. (1965). Aspects of the theory of syntax. Cambridge, MA: MIT Press.
Dronkers, N. F., \& Larsen, J. (2001). Neuroanatomy of the classical syndromes of aphasia. In R. S. Berndt (Ed.), Handbook of neuropsychology (2nd ed., pp. 19-30). Amsterdam: Elsevier.

Fahn, S., \& Elton, R. L. (1987). The Unified Parkinson's Disease Rating Scale (UPDRS). In S. Fahn, C. D. Marsden, D. B. Calne, \& M. Goldstein (Eds.), Recent developments in Parkinson's disease (Vol. 2, pp. 293-304). Florham Park, NJ: Macmillan.

Fodor, J. A. (1983). The modularity of mind: An essay on faculty psychology. Cambridge, MA: MIT Press.

Frazier, L. (1987). Syntactic processing: Evidence from Dutch. National Language and Linguistic Theory, 5, 519-560.

Freedman, M., \& Oscar-Berman, M. (1986). Selective delayed response deficits in Parkinson's and Alzheimer's disease. Archives of Neurology, 43, 886-890.

Friederici, A. D. (1985). Levels of processing and vocabulary types: Evidence from on-line comprehension in normals and agrammatics. Cognition, 19, 133-166.

Friederici, A. D. (1988). Agrammatic comprehension: Picture of a computational mismatch. Aphasiology, 2, 279-284.

Friederici, A. D. (1995). The time course of syntactic activation during language processing: A model based on neuropsychological and neurophysiological data. Brain and Language, 50, $259-281$.

Friederici, A. D. (1999). The neurobiology of language comprehension. In A. D. Friederici (Ed.), Language comprehension: A biological perspective (2nd ed., pp. 265-304). Berlin: Springer.

Friederici, A. D., Hahne, A., \& Mecklinger, A. (1996). The temporal structure of syntactic parsing: Early and late event-related brain potential effects elicited by syntactic anomalies. Journal of Experimental Psychology: Learning, Memory, and Cognition, 22, 1219-1248.

Friederici, A. D., Hahne, A., \& von Cramon, D. Y. (1998). First-pass versus second-pass parsing processes in a Wernicke's and a Broca's aphasic: Electro-physiological evidence for a double dissociation. Brain and Language, 62, 311-341.

Friederici, A. D., \& Kilborn, K. (1989). Temporal constraints on language processing: Syntactic priming in Broca's aphasia. Journal of Cognitive Neuroscience, 1, 262-272.

Friederici, A. D., Pfeifer, E., \& Hahne, A. (1993). Event-related brain potentials during natural speech processing: Effects of semantic, morphological and syntactic violations. Cognitive Brain Research, 1, 183-192.

Friederici, A. D., von Cramon, D. Y., \& Kotz, S. A. (1999). Language related brain potentials in patients with cortical and subcortical left hemisphere lesions. Brain, 122, 1033-1047.

Friederici, A. D., Wang, Y., Herrmann, C. S., Maess, B., \& Oertel, U. (2000). Localization of early syntactic processes in frontal and temporal cortical areas: A magnetoencephalographic study. Human Brain Mapping, 11, 1-11.

Goodglass, H. (1993). Understanding aphasia. San Diego, CA: Academic Press.

Gotham, A. M., Brown, R. G., \& Marsden, C. D. (1988). "Frontal" cognitive function in patients with Parkinson's disease "on" and "off" levodopa. Brain, 111, 299-321.

Graybiel, A. M. (1990). Neurotransmitters and neuromodulators in the basal ganglia. Trends in Neurosciences, 13, 244-254.

Groß, J., Ioannides, A. A., Dammers, J., Maess, B., Friederici, A. D., \& Müller-Gärtner, H.-W. (1998). Magnetic field tomography analysis continuous speech. Brain Tomography, 10, 273281.

Grossman, M., Carvell, S., Gollomp, S., Stern, M. B., Reivich, M., Morrison, D., et al. (1993). Cognitive and physiological substrates of impaired sentence processing in Parkinson's disease. Journal of Cognitive Neuroscience, 5, 480-498. 
Grossman, M., Carvell, S., Gollomp, S., Stern, M. B., Vernon, R. N., \& Hurtig, H. I. (1991). Sentence comprehension and praxis deficits in Parkinson's disease. Neurology, 41, 16201626.

Grossman, M., Carvell, S., Stern, M. B., Gollomp, S., \& Hurtig, H. I. (1992). Sentence comprehension in Parkinson's disease: The role of attention and memory. Brain and Language, 42, 347-384.

Grossman, M., Zurif, E., Lee, C., Prather, P., Kalmanson, J., Stern, M. B., \& Hurtig, H. I. (2002). Information processing speed and sentence comprehension in Parkinson's Disease. Neuropsychology, 16, 174-181.

Haarmann, H. J., \& Kolk, H. H. J. (1991). Syntactic priming in Broca's aphasia: Evidence for slow activation. Aphasiology, 5, 247-263.

Hagoort, P. (1993). Impairments of lexical-semantic processing in aphasia: Evidence from the processing of lexical ambiguities. Brain and Language, 45, 189-232.

Hagoort, P., Brown, C., \& Groothusen, J. (1993). The syntactic positive shift as an ERP-measure of syntactic processing. Language and Cognitive Processes, 8, 439-483.

Hahne, A., \& Friederici, A. D. (1999). Functional neurotopography of syntactic parsing: Early automatic and late controlled processes. Journal of Cognitive Neuroscience, 11, 193-204.

Hahne, A., \& Friederici, A. D. (2001). Processing a second language: Late learners' comprehension strategies as revealed by event-related brain potentials. Bilingualism: Language and Cognition, 4, 123-141.

Heaton, R. K. (1981). Wisconsin Card Sorting Test manual. Odessa, FL: Psychological Assessment Resources.

Hoehn, M. M., \& Yahr, M. D. (1967). Parkinsonism: Onset, progression, and mortality. Neurology, 17, 427-442.

Holcomb, P. J., \& Neville, H. J. (1991). Natural speech processing: An analysis using event-related brain potentials. Psychobiology, 19, 286-300.

Huynh, H., \& Feldt, L. A. (1970). Conditions under which mean square ratios in repeated measurement designs have exact Fdistributions. Journal of the American Statistical Association, 65, 1582-1589.

Indefrey, P., Hagoort, P., Herzog, H., Seitz, R. J., \& Brown, C. M. (2001). Syntactic processing in left prefrontal cortex is independent of lexical meaning. Neurolmage, 14, 546-555.

Inui, T., Otsu, Y., Tanaka, S., Okada, T., Nishizawa, S., \& Konishi, J. (1998). A functional MRI analysis of comprehension processes of Japanese sentences. NeuroReport, 9, 3325-3328.

Just, M. A., Carpenter, P. A., Keller, T. A., Eddy, W. F., \& Thulborn, K. R. (1996, October 4). Brain activation modulated by sentence comprehension. Science, 274, 114-116.

Kaan, E., Harris, A., Gibson, G., \& Holcomb, P. J. (2000). The P600 as an index of syntactic integration difficulty. Language and Cognitive Processes, 15, 159-201.

Kutas, M., \& Hillyard, S. A. (1984, January 12). Brain potentials during reading reflect word expectancy and semantic association. Nature, 307, 161-163.

Levin, B. E., Llabre, M. M., \& Weiner, W. J. (1989). Cognitive impairments associated with early Parkinson's disease. Neurology, 39, 557-561.

Lieberman, M. (2000). Intuition: A social cognitive neuroscience approach. Psychological Bulletin, 126, 109-137.

Lieberman, P., Kako, E., Friedman, J., Tajchman, G., Feldman, L. S., \& Jiminez, E. B. (1992). Speech production, syntax comprehension, and cognitive deficits in Parkinson's disease. Brain and Language, 43, 169-189.
Linebarger, M. C., Schwartz, M. F., \& Saffran, E. M. (1983). Sensitivity to grammatical structure in so-called agrammatic aphasics. Cognition, 13, 361-392.

McCarthy, G., \& Wood, C. C. (1985). Scalp distributions of event-related potentials: An ambiguity associated with analysis of variance models. Electroencephalography and Clinical Neurophysiology, 62, 203-208.

Moro, A., Tettamanti, M., Perani, D., Donati, C., Cappa, S. F., \& Fazio, F. (2001). Syntax and the brain: Disentangling grammar by selective anomalies. NeuroImage, 13, 110-118.

Mortimer, J. A., Pirozzolo, F. J., Hansch, E. C., \& Webster, D. D. (1982). Relationship of motor symptoms to intellectual deficits in Parkinson disease. Neurology, 32, 133-137.

Murray, L. L. (2000). Spoken language production in Huntington's and Parkinson's diseases. Journal of Speech, Language and Hearing Research, 43, 1350-1366.

Nadeau, S. E., \& Crosson, B. (1997). Subcortical aphasia. Brain and Language, 58, 355-402.

Natsopoulos, D., Grouios, G., Bostantzopoulou, G., Mentenopoulos, G., Katsarou, Z., \& Logothetis, J. (1993). Algorithmic and heuristic strategies in comprehension of complement clauses by patients with Parkinson's disease. Neuropsychology, 31, 951964.

Nishimura, N., Ogura, C., \& Ohta, I. (1995). Effects of the dopamine-related drug bromocriptine on event-related potentials and its relation to the law of initial value. Psychiatry and Clinical Neurosciences, 49, 79-86.

Oishi, M., Mochizuki, Y., Hara, M., Du, C. M., \& Takasu, T. (1996). Effects of intravenous L-dopa on P300 and regional cerebral blood flow in parkinsonism. International Journal of Neuroscience, 85, 147-154.

Osterhout, L., \& Holcomb, P. J. (1992). Event-related brain potentials, elicited by syntactic anomaly. Journal of Memory and Language, 31, 785-806.

Pascual-Leone, A., Grafman, J., Clark, K., Stewart, M., Massaquoi, S., Lou, J.-S., \& Hallet, M. (1993). Procedural learning in Parkinson's disease and cerebellar degeneration. Annals of Neurology, 34, 594-602.

Pell, M., \& Leonard, C. (2001). Susceptibility of nonverbal emotional processes to early Parkinson's disease. Movement Disorders, 16, S27.

Pfeifer, E., Novagk, R., \& Maess, B. (1995). Software for EEG/ ERP evaluation. In A. D. Friederici (Ed.), Max Planck Institute of Cognitive Neuroscience Leipzig annual report (pp. 5155). Leipzig, Germany: Max Planck Institute of Cognitive Neuroscience.

Phillips, A. G., \& Carr, G. D. (1987). Cognition and the basal ganglia: A possible substrate for procedural knowledge. Canadian Journal of Neurological Sciences, 14, 381-385.

Pinker, S. (1994). The language instinct: How the mind creates language. New York: Morrow.

Prather, P., Shapiro, L., Zurif, E., \& Swinney, D. (1991). Real-time examinations of lexical processing in aphasics. Journal of Psycholinguistic Research, 20, 271-281.

Robin, D. A., \& Schienberg, S. (1990). Subcortical lesions and aphasia. Journal of Speech and Hearing Disorders, 55, 90-100.

Sharbrough, F. W. (1991). Advances in epilepsy surgery offer patients new hope. Minnesota Medicine, 74, 9-12.

Sohn, Y. H., Kim, G. W., Huh, K., \& Kim, J.-S. (1998). Dopaminergic influences on the P300 abnormality in Parkinson's disease. Journal of Neurological Sciences, 158, 83-87.

Stromswold, K., Caplan, D., Alpert, N., \& Rauch, S. (1996). Localization of syntactic comprehension by positron emission tomography. Brain and Language, 52, 452-473. 
Tachibana, H., Aragane, K., Miyata, Y., \& Sugita, M. (1997). Electrophysiological analysis of cognitive slowing in Parkinson's disease. Journal of Neurological Sciences, 149, 47-56.

Tyler, L. K., \& Marslen-Wilson, W. D. (1986). The effects of context on the recognition of polymorphemic words. Journal of Memory and Language, 25, 741-752.

Ullman, M. T. (2001). A neurocognitive perspective on language: The declarative/procedural model. Neuroscience, 2, 717-726.

Ullman, M. T., Bergida, R., \& O'Craven, K. (1997). Distinct fMRI activation patterns for regular and irregular past tense [Abstract]. NeuroImage, 5, 549.

Ullman, M. T., Corkin, S., Coppola, M., Hickok, G., Growdon, J. H., Koroshetz, W. J., et al. (1997). A neural dissociation within language: Evidence that the mental dictionary is part of declarative memory, and that grammatical rules are processed by the procedural system. Journal of Cognitive Neuroscience, 9, $266-276$.

Yesavage, J. A., Brink, T. L., Rose, T. L., Lum, O., Huang, V., Adey, M. B., \& Leirer, V. O. (1983). Development and validation of a geriatric depression rating scale: A preliminary report. Journal of Psychiatric Research, 17, 37-49.

Zurif, E. B., Caramazza, A., \& Myerson, R. (1972). Grammatical judgements of agrammatic aphasics. Neuropsychologia, 10, 405-417.

Received December 18, 2001

Revision received July 1, 2002

Accepted August 6, 2002

\section{New Editors Appointed, 2004-2009}

The Publications and Communications Board of the American Psychological Association announces the appointment of five new editors for 6-year terms beginning in 2004.

Except where noted, as of January 1, 2003, manuscripts should be directed to the following individuals:

- For Psychology and Aging (http://www.apa.org/journals/pag.html), submit manuscripts to Rose T. Zacks, PhD, Department of Psychology, Michigan State University, East Lansing, MI 48824-1117.

- For Psychological Assessment (hitp://www.apa.org/journals/pas.html), submit manuscripts to Milton E. Strauss, PhD, Department of Psychology, Case Western Reserve University, Cleveland, $\mathrm{OH}$ 44106-7123.

- For Journal of Family Psychology (http://www.apa.org/journals/fam.html), submit manuscripts to Anne Kazak, PhD, ABPP, Oncology Psychosocial Research, The Children's Hospital of Philadelphia, Room 1486 (Market Street), 34th and Civic Center Boulevard, Philadelphia, PA 19104. For overnight couriers: Room 1486, 3535 Market Street, Philadelphia, PA 19104.

- For Joumal of Experimental Psychology: Animal Behavior Practices (http://www.apa.org/ journals/xan.html), submit manuscripts as of January 15 to Nicholas Mackintosh, Department of Experimental Psychology, University of Cambridge, Downing Street, Cambridge, CB2 3EB, United Kingdom.

- For Journal of Personality and Social Psychology: Personality Processes and Individual Differences section (http://www.apa.org/journals/psp.html), submit manuscripts to Charles S. Carver, PhD, Department of Psychology, University of Miami, P.O. Box 248185, Coral Gables, FL 33124-2070.

Electronic submission: As of January 1, 2003, authors will be expected to submit manuscripts electronically through the joumal's Manuscript Submission Portal (see the Web site listed above with each journal title). Authors who are unable to do so should correspond with the editor's office about alternatives.

Manuscript submission patterns make the precise date of completion of the 2003 volumes uncertain. Current editors Leah L. Light, PhD, Stephen N. Haynes, PhD, Ross D. Parke, PhD, Mark E. Bouton, $\mathrm{PhD}$, and Ed Diener, $\mathrm{PhD}$, respectively, will receive and consider manuscripts through December 31, 2002. Should 2003 volumes be completed before that date, manuscripts will be redirected to the new editors for consideration in 2004 volumes. 